\title{
"SINAES" CONTRADITÓRIOS: CONSIDERAÇÕES SOBRE A ELABORAÇÃO E IMPLANTAÇẨO DO SISTEMA NACIONAL DE AVALIAÇÃO DA EDUCAÇÃO SUPERIOR
}

\author{
GLADYS BEATRIZ BARREYRO* \\ José CARLOS Rothen ${ }^{*}$
}

\begin{abstract}
RESUMO: As posições no debate sobre a avaliação da educação superior, que se iniciou na década de 1980 , oscilam entre considerá-la como um processo interno de autoconhecimento institucional ou como ferramenta de regulação das instituições pelo Estado e/ou pelo mercado. Nesse contexto, o artigo trata do processo de elaboração e implantação do Sistema Nacional de Avaliação da Educação Superior (SINAES) no governo de Luiz Inácio Lula da Silva. Mostra-se que, na lei que o institui, estão presentes concepçôes antagônicas de avaliação e que essa recebe influências díspares como a do Programa de Avaliação Institucional das Universidades Brasileiras (PAIUB) e a do Exame Nacional de Cursos (ENC). Conclui-se que o SINAES tem o mérito de sinalizar uma mudança na concepção da avaliação com foco no mercado para a ênfase na melhoria da qualidade. Contudo, a indefinição do modelo de avaliação adotado mostra as oscilações da política de educação superior do governo Lula.

Palavras-chave: Educação superior. Avaliação da educação superior. Sistema Nacional de Avaliação da Educação Superior (SINAES). Regulação e avaliação. Controle da educação superior.
\end{abstract}

* Professora da Escola de Artes, Ciências e Humanidades da Universidade de São Paulo (UsP). E-mail: gladysb@usp.br

** Professor do Mestrado em Educação Superior do Centro Universitário do Triângulo (UnITRI). E-mail: jcrothen@bol.com.br

Educ. Soc., Campinas, vol. 27, n. 96 - Especial, p. 955-977, out. 2006

Disponível em <http://www.cedes.unicamp.br> 
“SINAES" contraditórios: considerações sobre a elaboração e implantação...

\author{
CONTRADICTORY "SINAES": CONSIDERATIONS ON THE \\ ELABORATION AND IMPLANTATION OF THE NaTiONAl HigheR \\ Education Evaluation System
}

ABSTRACT: In the debate on the evaluation of higher education which began in the 1980s, positions oscillate between considering it as an internal process of institutional self-knowledge or as a tool for the State and/or the market to regulate the Institutions. In this context, this paper deals with the process of elaboration and implantation of the National System of Higher Education Evaluation (SINAES) in the government of Luiz Inácio Lula da Silva. It shows that the law presents antagonistic conceptions of evaluation, which receive divergent influences from the Program of Institutional Evaluation of Brazilian Universities (PAIUB) and the National Test of Courses (ENC). It concludes that SINAES has the merit to signalize a change from the conception of evaluation centered on the market to an emphasis on quality improvement. However, the lack of a clear definition of a model to be adopted shows the lack of clarity in the higher education policies conducted under Lula's administration.

Key words: Higher education. Higher education evaluation. National System Of Higher Education Evaluation (SINAES). Regulation and evaluation. Higher education control.

\title{
Introdução
}

A avaliação assume, há três décadas, em diversos sistemas educacionais, o status de temática privilegiada na agenda da educação superior. O modelo de Estado que começa a se tornar hegemônico no mundo ocidental, a partir de então, questiona o financiamento público de algumas instituiçôes sociais, como as universidades.

Essa instituição - que, até então, garantia sua qualidade pela sua própria excelência, tendo como base a autonomia e uma forte tradição de auto-regulação - enfrenta uma crise de legitimidade, porque a própria condição do conhecimento como bem social é questionada, pela incorporação da lógica de mercado a múltiplos aspectos da vida social. ${ }^{1}$

As instituições são impelidas a cumprir um papel-chave no novo modelo econômico-social: "Todos têm interesse na qualidade da universidade, entre outras razóes porque a ciência-tecnologia tornou-se mercadoria-chave, ao lado do trabalho, da acumulação de capital" (Sguissardi, 2006, p. 4). 
Concomitantemente à emergência de processos de mundialização e globalização, tem-se dinâmicas de intercâmbio, cooperação e mobilidade de recursos humanos que, junto à mercantilização da educação superior, introduzem a competitividade entre os sistemas, especialmente nos países desenvolvidos, de cuja nova tendência o processo de Bolonha, ${ }^{2}$ desencadeado pela Comunidade Européia em 1999, é um exemplo.

A avaliação na educação superior é indissociável desses cenários, mas pode cumprir funçôes diferentes, de acordo com os valores do sistema no qual está inserida, pois diferentes paradigmas epistemológicos a fundamentam, segundo a educação seja concebida como bem público ou com uma lógica de mercado (Dias Sobrinho, 2004).

Algumas das finalidades da avaliação têm sido: oferecer parâmetros que garantam a qualidade da educação para os usuários e os empregadores, favorecer a melhoria da qualidade dos serviços, servir de instrumento de prestação de contas, estimular e regular a concorrência entre instituições, implantar mecanismos de controle do investimento dos recursos públicos, supervisar a iniciativa privada na provisão de um bem público, reconhecimento de créditos entre programas e aptidão para receber recursos públicos (Rodríguez Gómez, 2004, p. 2).

Diferentes autores têm desenvolvido estudos e modelos teóricos para analisar esses usos da avaliação. $\mathrm{Na}$ América Latina: avaliação como controle versus avaliação como produção de sentidos/emancipatória (Dias Sobrinho, 2002), avaliação como garantia pública de qualidade versus avaliação para a melhoria da qualidade (Stubrin, 2005), avaliação como regulação versus avaliação democrática (Contera, 2002), entre outros. Tais concepçóes podem se sintetizar em duas vertentes: as que permitem identificar a avaliação como controle, respondendo a uma lógica burocrático-formal de validade legal de diplomas e habilitações profissionais em âmbito nacional, e as com função formatival emancipatória, sob uma lógica acadêmica, com o intuito de subsidiar a melhoria das instituições.

A história da avaliação brasileira da educação superior está inserida nesse contexto. Neste artigo far-se-á um balanço crítico da elaboração e implantação do Sistema Nacional de Avaliação da Educação Superior (SINAES) no governo Lula, procurando explicitar as concepções de avaliação adotadas e identificar avanços e retrocessos nesse processo. 
“SINAES" contraditórios: considerações sobre a elaboração e implantação...

A avaliação da educação superior no Brasil

Diversos programas e propostas, que antecedem à sanção da Constituição de 1988, compõem a pré-história da avaliação da educação superior; desses, destacam-se o Programa de Avaliação da Reforma Universitária (PARU), em 1983; o relatório da Comissão de Notáveis, em 1985, e a proposta de avaliação no anteprojeto do Grupo Executivo da Reforma da Educação Superior (GERES), em 1986. A perspectiva que prevalecia - a avaliação quantitativa e objetivista - antecipava as comissões de especialistas para a avaliação de cursos de graduação e a aplicação de testes padronizados aos concluintes (Bertolin, 2004, p. 68), que seriam procedimentos utilizados depois de 1996. Em 1988, a Constituição Cidadã incorpora a avaliação, pois, ao mesmo tempo em que declara a educação livre à iniciativa privada, prevê que ela está submetida ao cumprimento das normas gerais da educação nacional: a autorização e avaliação de qualidade pelo poder público (art. 209).

Como reação às concepções quantitativistas, é criado, em 1993, o Programa de Avaliaçãoo Institucional das Universidades Brasileiras (PAIUB), produto do trabalho da Comissão Nacional de Avaliação das Universidades Brasileiras, composta por membros de entidades representativas do setor $^{3}$ (PAIUB, 1994). O Programa caracterizava-se como uma proposta de auto-regulação e concebia a avaliação como institucional (o foco era a própria instituição), a adesão era de caráter voluntário e propiciava a participação dos próprios integrantes. Previa a criação de uma comissão de avaliação no interior de cada instituição, que elaboraria um projeto de auto-avaliação. Embora tendo a sua origem nas próprias Instituições de Educação Superior (IES), o Ministério da Educação (MEC) era quem financiava e realizava a (meta) avaliação dos projetos, inspirados no "Documento Básico de Avaliação das Universidades Brasileiras".

Essa forma de avaliação corresponde à concepção formativa/emancipatória, baseada na auto-regulação, na qual a participação da comunidade acadêmica é fundamental, como aconteceu de fato tanto na criação quanto na implementação da proposta. $\mathrm{O}$ PAIUB chegou a ser desenvolvido por algumas universidades ${ }^{4}$ e, sem ser extinto formalmente, foi relegado pela adoção do Provão, em 1997.

No governo Fernando Henrique Cardoso, o então ministro da Educação, Paulo Renato de Souza, implantou uma sistemática de avaliação desenvolvida de acordo com as necessidades da política de 
educação superior. Este processo estava sendo implementado, tendo como mola propulsora as reaçôes da comunidade acadêmica e da sociedade. As propostas apareceram num conjunto de atos legislativos que foram sendo editados ao longo de todo o governo, estabelecendo a competência do MEC na avaliação periódica dos cursos de avaliação, implantando o Exame Nacional de Cursos (ENC - Provão), dispondo sobre a avaliação de instituições e cursos e atrelando a renovação de reconhecimento de cursos aos resultados do Provão e da Avaliação das Condições de Ensino.

O Provão foi o instrumento de avaliação privilegiado, uma vez que os outros (Avaliação das Condições de Oferta, para os cursos, e Avaliação Institucional, para as IES) tinham menor destaque na divulgação oficial, sendo os seus resultados utilizados para efeitos regulatórios no reconhecimento de cursos de graduação. A implantação desses instrumentos ocorreu na mesma época da aprovação da LDB, a qual determinava que a autorização de funcionamento de instituições e o reconhecimento de cursos seriam por prazo limitado e vinculados à realização de avaliações (art. 46). Essas mudanças, introduzidas pela LDB e com a sua posterior regulamentação, permitiram a expansão do ensino superior pela via privada.

O Provão foi um mecanismo de regulação estatal com critérios relacionados ao mercado, com estabelecimento de rankings que estimulavam a concorrência entre as IES. Apesar das normas preverem punições nos casos de resultados negativos no Provão, na prática não houve nenhum efeito punitivo, senão de divulgação midiática e publicitária em procedimentos de auto-regulação típicos do mercado.

\section{A elaboração do SINAES 5}

Na proposta do programa de governo da coligação "Lula Presidente", a avaliação foi um aspecto destacado nas políticas para a educação superior, sendo um contraponto à autonomia institucional. Pretendia-se que a avaliação da educação superior fosse além da visão neoliberal, a qual estimula a concorrência entre as instituiçóes e a regulação pelo mercado consumidor.

A avaliação é compreendida como "instrumento para o planejamento e a intervenção do Estado, visando à melhoria do desempenho dos alunos e à melhoria do sistema de ensino" (Coligação Lula Presi- 
“SINAES" contraditórios: considerações sobre a elaboração e implantação...

dente, 2002, p. 4). Entendia-se que a nova proposta deveria ser inspirada nas experiências anteriores, entre outras, a do PAIUB (p. 29).

No clima de primeiro ano de governo, foi criada a Comissão Especial de Avaliação da Educação Superior (CEA), ${ }^{6}$ com prazo de 120 dias para elaborar propostas e subsídios para alteração da Avaliação da Educação Superior. A comissão foi composta por representantes da Secretaria da Educação Superior (SESu,) do Instituto Nacional de Estudos e Pesquisas Educacionais Anísio Teixeira (INEP), da Coordenação de Aperfeiçoamento de Pessoal de Nível Superior (CAPES), da União Nacional dos Estudantes (UNE) e de especialistas ligados às universidades públicas e privadas. ${ }^{7}$ Observa-se, na composição da comissão, a predominância do perfil acadêmico de seus integrantes, especialmente das universidades públicas que participaram de experiências de avaliação no âmbito do PAIUB.

Nesse momento, a questão apresentada para a opinião pública referia-se à validade da realização ou não do Exame Nacional de Cursos. São representativas desse debate as posições de Cristovam Buarque, na época ministro da Educação, e a de Otaviano Helene, então presidente do INEP - autarquia ligada ao próprio MEC e executora das avaliações -, mostrando dessa forma, publicamente, as diferenças no interior do próprio Ministério.

Buarque (2003), em texto intitulado "Avaliando a avaliação", defendia a necessidade da avaliação da educação superior. Apesar de ressalvar que o Provão era um instrumento parcial de avaliação, afirmava que a proposta de avaliação institucional implantada na Universidade de Brasília (UNB), na sua gestão como reitor dessa Instituição, teve o seu complemento com a implantação do Provão, pelo seu antecessor Paulo Renato Souza.

Em contraposição à postura do ministro, que defendia a continuação do Provão, Helene (2003) publicou, no site do órgão, o artigo "O INEP e as avaliações", afirmando que o Provão era severamente criticado, principalmente pela forma de divulgação dos resultados. ${ }^{8}$

Em 2 de setembro de 2003, a CEA apresentou publicamente a sua proposta, sendo a avaliação institucional o seu centro. A ênfase da concepção avaliativa exposta está na preocupação com a tomada de consciência sobre a instituição, conseguida pela participação coletiva em todo o processo, o que lhe outorga caráter formativo e de aperfeiçoamento individual e institucional. $\mathrm{O}$ processo estaria centrado na auto- 
avaliação, realizada no interior das instituições, com subcomissões internas que avaliariam os diferentes cursos. Outros dados para a avaliação seriam advindos de um exame do Processo de Avaliação Integrado do Desenvolvimento Educacional e da Inovação da Área (PAIDEIA), aplicado a uma amostra de alunos de segundo e do último ano das instituições, com o intuito de analisar os processos educativos em cada área de conhecimento, além de informações estatísticas coletadas regularmente pelo MEC. A auto-avalição seria completada com um momento de avaliação externa realizada por membros da comunidade acadêmica e científica, por meio de visitas in loco, com o objetivo de contrastar as informaçōes provindas do relatório de auto-avaliação institucional (CEA, 2004). O relatório final, derivado das variadas instâncias, seria remetido ao órgão encarregado da avaliação, criado para tal fim: a Comissão Nacional de Avaliação da Educação Superior (CONAES).

A difusão da proposta gerou um debate divulgado pela imprensa, ${ }^{9}$ destacando as opiniões de ex-membros do governo anterior que haviam participado da elaboração e implantação da sistemática de avaliação, tais como o ex-ministro Paulo Renato Souza, a ex-presidente do INEP, Maria Helena Guimarães de Castro, e a ex-conselheira do CNE, Eunice Durham. Defendiam a visão neoliberal da avaliação como controle, mediante a classificação das instituições e cursos, baseada no resultado do Provão, e criticavam a avaliação institucional por considerá-la subjetiva, enquanto que o resultado das provas era considerado objetivo. ${ }^{10}$

A imprensa ${ }^{11}$ divulgava idéias a favor da manutenção do Provão. $\mathrm{O}$ ministro Buarque afirmou, então, que era a favor do ranking de instituições utilizando não apenas a prova como critério. ${ }^{12}$ No sentido de reverter a tendência da avaliação estritamente emancipatória defendida pela CEA, Buarque entendia que "Duas coisas ficaram meio patológicas: uma é achar que o método de avaliação (o Provão) é perfeito e outra é achar que uma proposta feita por uma comissão, pela qual eu tenho o maior respeito, já é o documento que vai substituir a avaliação anterior" (O Estado de S. Paulo, 8 set. 2003).

No dia 2 de dezembro de 2003, o ministro encaminhou à Câmara uma nova proposta de avaliação, não mais intitulada SINAES, mas SINAPES (Sistema Nacional de Avaliação e Progresso do Ensino Superior), divulgada em um folheto de 10 páginas - com uma redação mais próxima à utilizada em propaganda - denominado IDES. A nova geração na avaliação da Educação Superior Brasileira. 
“SINAES" contraditórios: considerações sobre a elaboração e implantação...

Nessa nova proposta, o resultado final da avaliação seria expresso pelo Índice de Desenvolvimento da Educação Superior (IDES), inspiração no Índice de Desenvolvimento Humano (IDH) das Nações Unidas. O IDES seria composto por quatro índices: 1) a avaliação do ensino (medido através das características e produtividade do corpo docente), 2) a avaliação da aprendizagem (apresentada como uma evolução do Provão e adotando características do Paidéia), 3) a avaliação da capacidade institucional (que estaria centrada na infra-estrutura) e 4) a avaliação da responsabilidade social (que destacava as atividades de extensão universitária).

A proposta de Buarque buscou conciliar algumas das idéias da CEA - por exemplo, a realização de um exame nacional por amostragem - com a manutenção da sistemática de fazer ranking das instituições, somado um elemento próprio: a responsabilidade social.

$\mathrm{Na}$ discussão da concepção de avaliação a ser adotada, as duas propostas tinham fundamentos opostos: a CEA defendia a avaliação emancipatória, o IDES apoiava-se na avaliação somativa, tendo o seu resultado expresso em um único número, induzindo o ranking das instituições.

Treze dias após a apresentação da proposta do ministro para debate na Câmara, é editada a Medida Provisória (MP) n. 147/2003. Esta, além de não respeitar a dinâmica da discussão proposta pelo próprio MEC, não faz nenhuma referência ao IDES, nem a nenhum outro índice. Preservam-se apenas os quatro aspectos que comporiam a avaliação do sistema (ensino, aprendizagem, capacidade institucional e responsabilidade social) e a existência de duas comissões ministeriais (em lugar da CONAES): uma executiva e outra deliberativa, as quais implementariam a avaliação. $\mathrm{Na} \mathrm{MP}$, foram fortalecidos o MEC e o INEP como os principais agentes da avaliação, sendo omissa em relação a aspectos importantes, como a avaliação da pós-graduação, e dúbia ao definir de quem seria a atribuição de divulgar os resultados. ${ }^{13}$ Como virtude dessa MP, destaque-se, no artigo 11, que o resultado da avaliação seria expresso em três níveis (satisfatório, regular e insatisfatório): dessa maneira, o resultado final da avaliação não facilitaria a criação de rankings.

No início de 2004, o presidente Lula realizou uma reforma ministerial, trocando, entre outros, o ministro da Educação, assumindo Tarso Genro, em 27 de janeiro de 2004. Na Câmara dos Deputados, o relator do projeto de Lei de Conversão da MP apresentou proposta que 
alterou totalmente o conteúdo da MP n. 147/2003. Ao ser aprovada no Congresso Nacional, a lei recebeu o número 10.861 e foi sancionada pelo presidente da República, em 14 de abril de 2004. Posteriormente, ela foi regulamentada pela Portaria do MEC n. 2.051, de 9 de julho de 2004.

A lei e as suas fontes

Apesar de a Lei n. 10.861/04 resgatar o nome "Sistema Nacional de Avaliação da Educação Superior" (SINAES) utilizado na proposta da CEA e do documento dessa Comissão preceder à lei no site do INEP, ${ }^{14}$ uma análise mais apurada mostra importantes diferenças entre ambos, assim como a influência das experiências anteriores de avaliação em pontos importantes da lei.

As questôes analisadas a seguir pretendem identificar na lei as origens, filiaçôes e diferenças no que diz respeito a) à função da avaliação, b) à definição das agências principais da avaliação, c) ao foco da avaliação, d) ao exame de desempenho acadêmico e e) à divulgação dos resultados, realizando comparações entre o texto da Lei n. 10.861/04, o "Programa de Avaliação Institucional das Universidades Brasileiras", o ENC-Provão, o texto IDES. A nova geração na avaliação da Educação Superior Brasileira, a MP 147/03 e a proposta da CEA "Sistema Nacional de Avaliação da Educação Superior, bases para uma nova proposta de avaliação da educação superior brasileira".

\section{a) Função da avaliação}

Na proposta da CEA, a função principal da avaliação é entendida como emancipatória, e o agente principal é a comunidade interna das IES, como no PAIUB; por sua vez, na lei, a função é o controle e os agentes principais são as agências do Estado (Rothen \& Shulz, 2005), que a constituem numa lei hibrida (Bertolin, 2004).

\section{b) Agências da avaliação}

Enquanto no governo Fernando Henrique, o INEP tornou-se o órgão governamental responsável pela avaliação da educação superior, ${ }^{15}$ na proposta da CEA era prevista a criação da Comissão Nacional de Avalia- 
“SINAES" contraditórios: considerações sobre a elaboração e implantação...

ção da Educação Superior (CONAES) como o núcleo coordenador e executor da avaliação. Mas, na lei aprovada, a CONAES tem menos atribuiçôes que as previstas na proposta, pois as atribuições de coordenar e executar são divididas respectivamente entre a CONAES e o INEP (Rothen \& Shulz, 2005). Quanto à divulgação dos resultados da avaliação, na proposta da CEA seriam divulgados pela CONAES; já na legislação, o responsável é o MEC. Ressalta-se que na Lei n. 10.861/04 é ignorada a sugestão da CEA de atribuir as seguintes competências à CONAES: oferecer apoio técnico às instituições, realizar a articulação entre os instrumentos de avaliação e analisar os resultados globais, tendo sofrido um esvaziamento de funçóes que a transformaram de uma agência executiva em uma consultiva (Barreyro, 2006).

\section{c) $\mathrm{O}$ foco da avaliação}

Apesar de não terem sido desenvolvidas, a legislação promulgada ${ }^{16}$ na gestão do ex-ministro Paulo Renato incluía as análises do sistema nacional para subsidiar políticas de educação superior. Também a proposta da CEA atribuía essa função à CONAES. Na Lei n. 10.861/04, essa atribuição reduziu-se à prescrição de que a avaliação deve "orientar a expansão de sua oferta" (art. $1^{\circ}, \$ 1$ ).

$\mathrm{Na}$ proposta da CEA, o foco da avaliação são as instituições, sendo a avaliação de cursos e o PAIDEIA apresentados como instrumentos da avaliação, subsidiários à avaliação institucional (CEA, 2004, p. 125). O documento resgata a idéia do PAIUB de que a avaliação sempre é institucional, propondo sua realização a partir de dez dimensões que envolvem todas as funções da instituição. ${ }^{17}$

O SINAPE, instituído pela MP n. 147/03, é determinante na configuração final da lei, pois inclui os três eixos: as instituições, os cursos e a prova que serão constitutivos do modelo final do SINAES. Deve-se a ela a re-incorporação da avaliação de cursos, destacada no documento sobre o IDES: "a base da avaliação do processo de ensino será o conjunto de informaçōes relativas ao corpo docente contidas na Avaliação das Condições de Ensino" (p. 4), recuperando, inclusive, o nome do instrumento desenvolvido durante a gestão de Paulo Renato.

Por sua vez, a Lei n. 10.861/04 prevê que será realizada a avaliação das instituiçóes de educação superior, dos cursos de graduação e do 
desempenho acadêmico de seus estudantes $\left(\right.$ art. $1^{\circ}$ ). Dentro do estabelecido pela lei, cada uma das avaliações pode ser realizada de maneira independente, sendo que para cada uma delas é atribuído um conceito numa escala com cinco níveis (art. 3, $\$ 3$ ).

Assim, a Lei n. 10.861/04 foca o objeto da avaliação nas instituições, nos cursos e nos estudantes, recuperando aspectos parciais de cada uma das experiências avaliativas anteriormente realizadas, re-configuradas, mas exclui a menção explícita à análise global dos resultados do sistema que estava prevista na desarticulada sistemática de avaliação vigente, até a sanção da lei que instituiu o SINAES.

\section{d) $\mathrm{O}$ exame de desempenho acadêmico}

A realização de uma prova é um outro elemento metamorfoseado: Provão/PAIDEIA/ENADD/ENADE. O Provão, aplicado aos estudantes formandos, foi o instrumento privilegiado para avaliar a qualidade dos cursos com vistas à regulação e ao controle das instituições pelo mercado.

O PAIDEIA, proposto pela CEA, estava orientado a ser um dos instrumentos que fornecesse informaçôes para os processos da auto-avaliação e da avaliação institucional interna e externa e foi concebido para compreender as dinâmicas da formação, do desenvolvimento e da inovação de cada área e não simplesmente o resultado final (CEA, 2004, p.110-114). Seria aplicado a estudantes, segundo critérios amostrais e em diferentes momentos da formação, organizados por área e não por curso. Assim, o PAIDEIA seria um instrumento para a avaliação institucional e não o elemento central da avaliação de cursos, como era o Provão.

Entre o documento da CEA e a lei aprovada, a MP n. 147/2003 menciona uma avaliação do "processo de aprendizagem" (art. $1^{\circ}$ ) sem maiores especificaçôes, apesar de o IDES, no folheto já citado, explicar que o indicador de aprendizagem seria "o Exame Nacional de Desempenho do Corpo Discente"18 (ENADD). O folheto também informava que a comparação entre a primeira e a segunda prova mostraria o avanço realizado pelo aluno graças ao curso, "independentemente da formação recebida antes" (p. 4).

Ao comparar o ENADD com o PAIDEIA, destacam-se as seguintes diferenças: no PAIDEIA, a prova seria aplicada aos alunos do segundo e do último ano; o enfoque seria nas grandes áreas e teria como referência a 
“SINAES" contraditórios: considerações sobre a elaboração e implantação...

formação e os processos; por sua vez, no ENADD, a prova é aplicada aos alunos do primeiro e do último ano, isto é, retoma-se o foco do Provão - o curso -, tendo-se como base da avaliação o desempenho do aluno.

Já o ENADE, aprovado pela Lei n. 10.861/04, possui poucas características do PAIDEIA, mantém a idéia do ENADD, no que diz respeito às provas no primeiro e no último ano do curso, e admite "a utilização de procedimentos amostrais" (art. $5, \$ 2^{\circ}$ ), como no PAIDEIA. O foco é o "desempenho dos estudantes dos cursos" (art. 5). O ENADE, no entanto, não é um instrumento da avaliação institucional apenas, como o PAIDEIA, e não é a avaliação do curso como o Provão, senão um dos três componentes da avaliação das instituições.

O processo aqui relatado mostra os avatares de uma prova em longa escala aplicada aos estudantes da educação superior e suas metamorfoses, que foi se constituindo como uma colcha de retalhos: de um exame censitário a um outro por amostragem, de todos os cursos, a áreas $\mathrm{e}$ a amostra de cursos, de formandos a ingressantes e concluintes. No fim, persiste a avaliação do produto educação, apesar das críticas sucessivas, o que nos conduz às "condicionalidades" das agências internacionais de empréstimo (Barreyro, 2004).

\section{e) A divulgação dos resultados}

$\mathrm{Na}$ legislação anterior, os resultados, principalmente do Provão, eram apresentados de forma a estabelecer-se um ranking dos cursos e instituiçōes. Já a CEA propôs que a CONAES divulgasse como resultados os pontos fortes e fracos de cada instituição. Com essa sistemática não seria possível estabelecer nenhum tipo de ranking; contudo, essa opção não escapa totalmente da visão da educação como "mercadoria", pois os resultados divulgados por instituição permitem que o "consumidor" de educação escolha o melhor curso para ser "adquirido".

Na MP n. 147/03, artigo 11, estabelecia-se que o resultado da avaliação das IES fosse expresso em um conceito, numa escala de três níveis, com viés qualitativo: satisfatório, regular, insatisfatório. A opção adotada diminuía significativamente a possibilidade de se estabelecer ranking.

Finalmente, na Lei n. 10.861/04 retoma-se a escala de cinco conceitos a ser atribuída como resultado de cada uma das avaliaçôes (Institucional, Curso e ENADE). Interessante notar que, além de reto- 
mar a possibilidade do criticado ranking, a lei também resgata a possibilidade de compartimentalização da avaliação, ao prever a divulgação separada dos resultados.

O breve apanhado realizado até aqui mostra a persistência de duas concepções de avaliação: a do PAIUB e a do ENC-Provão e suas metamorfoses. Assim, coexistem na Lei n. 10.861/04 a visão formativa/ emancipatória do PAIUB - recuperada pela CEA na proposta de auto-avaliação - e a de controle, aferição de produto do ENC-Provão.

\section{Lei aprovada, a polêmica continua ${ }^{19}$}

Encerrado o momento legislativo - aprovação da lei e edição das portarias de regulamentação -, as duas concepções de avaliação continuam coexistindo. Sintomático dessa indefinição é a adoção de concepções divergentes nos sucessivos documentos publicados pela CONAES/ INEP; por exemplo, os documentos intitulados Diretrizes para a avaliação das Instituições de Educação Superior e o Roteiro para a Avaliação Interna são mais próximos da concepção emancipatória defendida pela CEA do que da visão regulatória da avaliação. Por sua vez, o documento Avaliação Externa de Instituiçôes de Educação Superior assume a visão oposta.

No início das Diretrizes, os autores do documento vinculam o conceito da avaliação institucional à definição presente na proposta da CEA e a seus antecessores como o PAIUB: a avaliação institucional tem a auto-avaliação como central (CONAES/INEP, 2004a, p. 7). Contudo, a vinculação entre avaliação e regulação segue a mesma estrutura presente na proposta da CEA, dividindo o processo em três momentos: 1) o poder público aplica a regulação para a autorização de funcionamento das IES e credenciamento dos cursos; 2) avaliação realizada autonomamente pelas IES; 3) o poder público, tendo como base o parecer da CONAES, aplica os efeitos regulatórios (CONAES/INEP, 2004a, p. 10).

A avaliação, que é o segundo momento do processo descrito, também foi dividida em três momentos: 1) Inicia-se com (auto) avaliação institucional coordenada pela Comissão Própria de Avaliação ( $\mathrm{CPA})$ de cada IES. 2) O relatório da CPA é encaminhado para avaliação externa, com o objetivo de corrigir os erros de percepção da avaliação interna. 3) A comissão externa, com base no relatório interno, encaminha o seu para a CONAES, que irá elaborar o relatório final (idem, ibid., p. 22). 
“SINAES" contraditórios: considerações sobre a elaboração e implantação...

Em última instância, os efeitos regulatórios da avaliação teriam como base a auto-avaliação institucional.

O documento, Avaliação Externa de Instituiçōes de Educação Superior: Diretrizes e Instrumento, inicia com a afirmação de que a avaliação externa deve ser formativa e, no decorrer do mesmo, separa-se a auto-avaliação da avaliação externa. A justificativa utilizada para esta separação é que existiriam dois tipos de referências: a particular e a universal. Na particular, "a definição de padrôes de qualidade está ligada aos objetivos que direcionam o processo educativo e ao projeto pedagógico e científico da IES". Na universal, busca-se identificar "a adequação e a pertinência dos processos de formação, o rigor acadêmico e científico, a condição social, científica e cultural da produção acadêmica, a construção da cidadania e o exercício da democracia" (CONAES/INEP, 2005, p. 11). Finalmente, o documento aproxima-se da dinâmica da avaliação do governo anterior, na qual se definia um conjunto de indicadores com seus respectivos pesos que possibilitavam a elaboração de um conceito final.

\section{CPA: a auto-avaliação no SINAES}

A avaliação institucional no SINAES recupera a idéia do PAIUB e da CEA quanto à prescrição de que as instituições elaborem uma proposta de auto-avaliação com a participação ativa dos seus membros. Enquanto no PAIUB a adesão ao programa era voluntária, a auto-avaliação é um momento obrigatório no SINAES.

Para a realização desse aspecto do SINAES, a CONAES apresentou, em 2004, o "Roteiro de auto-avaliação institucional". Nesse documento, os assuntos sugeridos para as instituiçôes elaborarem as suas propostas de auto-avaliação são organizados em dez dimensões, correspondentes às estabelecidas na Lei n. 10.861/04 que, por sua vez, recupera as dimensões que estruturariam a avaliação institucional na proposta da CEA. No documento, a CONAES manifesta a idéia de que as instituições podem ou não seguir essas dimensões, incorporar ou mudar outras, coerentemente com o enfoque de que a avaliação é um processo interno.

Para a coordenação da auto-avaliação, a Lei n. 10.861/04 (art. 11) determina a criação de uma Comissão Própria de Avaliação (CPA), no interior de cada instituição, com representação da sociedade civil e de todos os segmentos da comunidade. 
A identidade das CPAs depende do grau de autonomia e liberdade que elas possam efetivamente conseguir nas instituiçôes, podendo adquirir características centralizadoras, burocráticas, utilitaristas ou emancipatórias, dependendo do grau de envolvimento dos atores institucionais e do uso que a auto-avaliação tenha no interior da instituição. Apesar da legislação declarar a autonomia das CPAs em relação aos colegiados e órgãos da instituição, o cumprimento desta é um ato que depende da vontade política institucional e da estrutura organizacional. O caráter público/ privado e/ou comunitário/confessional/filantrópico pode ser uma variável com forte influência no tipo de CPA que vai ser construída em cada IES.

À formação das CPAs seguiu um acompanhamento da CONAES, determinando prazos de entrega das propostas/projetos de auto-avaliação. As propostas foram devolvidas às instituiçôes com pareceres cujo fim era "prestar orientaçóes que possam ser úteis ao desenvolvimento do trabalho das CPAs" (CONAES, 2005). A CONAES pretendeu resguardar a autonomia institucional no que diz respeito a essas propostas/projetos, resgatando os procedimentos do PAIUB e da CEA.

Apesar de possíveis limitações e distorções, é importante o fato da auto-avaliação e as CPAs estarem institucionalizadas em mais de 2.000 Instituições de Ensino Superior, com o seu potencial de apropriação e transformação institucional (Barreyro, 2006).

\section{Contradições que precisam de "pontes"}

Em 9 de maio de 2006, é promulgado o Decreto 5.773 - chamado pelo próprio Ministério de decreto ponte entre avaliação e regulação -, que havia sido colocado para discussão pública em fevereiro do mesmo ano.

O decreto tinha como papel substituir o Decreto n. 3.860, de 9 de julho de 2001, que dispunha sobre a organização do ensino superior e regulamentava a Lei n. 9.131/95 nos aspectos relativos aos procedimentos da avaliação. Na prática, o decreto ponte significa a antecipação de alguns pontos da reforma universitária - principalmente ao tratar da organização da educação superior - e também uma nova regulamentação do SINAES.

O decreto parece ser a tentativa de conciliar as tendências presentes nos diversos documentos publicados no âmbito do MEC/CONAES/ 
“SINAES" contraditórios: considerações sobre a elaboração e implantação...

INEP. Na sua estruturação, o decreto assume a tese defendida pela Comissão Especial de Avaliação na sua proposta, retomada na orientação das Diretrizes para a Avaliação das Instituiçōes de Educação Superior, de que a regulação/avaliação ocorre em três momentos distintos: a) a regulação pelo poder público nas etapas iniciais da autorização e credenciamento; b) a avaliação e c) a aplicação pelo poder público dos efeitos regulatórios da avaliação.

Em comparação à lei que institui o SINAES, o Decreto n. 5.773/06 traz como novidade que os atos de credenciamento/autorização e o recredenciamento dos cursos e instituições são de responsabilidade das Secretarias do MEC e do Conselho Nacional de Educação (art. 5 e 6) - aspectos que receberam prescriçóes no Decreto n. 3.860/01. O decreto repete que é de competência da CONAES coordenar e supervisionar o SINAES. Repete, também, que é de competência do INEP "elaborar os instrumentos de avaliação, conforme as diretrizes da CONAES", e lhe atribui a competência de "elaborar os instrumentos de avaliação para credenciamento de instituições e autorização de cursos, conforme as diretrizes das Secretarias e do CNE (art. 7)".

A opção adotada no decreto de prever, primeiro, que as Secretarias do MEC e o CNE determinarão as diretrizes para a elaboração de instrumentos de avaliação, tendo em vista o credenciamento, e, segundo, que é competência da CONAES estabelecer as diretrizes para a avaliação das IES e cursos, tem as seguintes dificuldades: a) as diretrizes podem ser contraditórias entre si; b) a diretrizes podem ter como pressuposto concepçôes distintas de educação superior; c) haverá duplicação de esforços governamentais para a realização de tarefas próximas.

No decreto, segue-se a mesma tendência presente no documento Avaliação Externa de Instituiçōes de Educação Superior de separar a autoavaliação da avaliação externa, retirando assim a centralidade da auto-avaliação. Essa interpretação é reforçada pelo fato de que, na Lei n. 10.861/ 04 , tem-se, no inciso I do artigo 2, a expressão "avaliação institucional, interna e externa". Note-se que as duas estão juntas. Por sua vez, no decreto, parágrafo $1^{\circ}$ do artigo 58 , as duas são apresentadas como processos distintos.

Com o decreto ponte, a lei que institui o sINAEs é "re-elaborada": por um lado, retoma o princípio da separação entre a regulação e a avaliação; por outro, reforça a visão da separação entre a auto-avaliação e a 
avaliação externa, deixando transparecer que esta faz parte do processo de regulação e supervisão. As conseqüências do decreto na re-configuração do SINAES dependem da maneira como ele será interpretado e aplicado posteriormente.

Consideramos importante que a avaliação seja realizada por órgão distinto do regulador e supervisor pelas seguintes razóes: a) como a avaliação exige processos complexos e que requerem o dispêndio de muito trabalho, é aconselhável que ela seja realizada por um órgão especializado; b) como a avaliação, a regulação e a supervisão moldam uma realidade, a divisão das atividades implica a diluição do poder em determinar os modelos de educação superior a serem adotados. Contudo, entendemos que, devido ao dispêndio de esforços e recursos, a avaliação promovida por agências estatais não pode ser considerada como um processo à parte da regulação, como pretendia a proposta inicial da CEA.

\section{Considerações finais}

O SINAES foi estabelecido por uma lei aprovada pelo Congresso e sancionada pelo presidente da República, um ano depois do início do governo Lula, sendo esse um dos poucos atos legislativos educacionais desse governo. A lei aprovada implica a criação de um Sistema de Avaliação e não de instrumentos isolados estabelecidos por leis, decretos e portarias ministeriais.

O SINAES sinaliza uma mudança na concepção da avaliação, passa do foco da concorrência institucional pelo mercado para o da melhoria da qualidade, afirmando valores ligados à educação superior como bem público e não como mercadoria (art. $1 \$ 1^{\circ}$ ).

Mas, o SINAES é o resultado da cumulação e da metamorfose. Os três pilares que constituem o Sistema atualmente são derivados das experiências anteriores: a) a Avaliação Institucional, do PAIUB, b) a Avaliação dos Cursos de Graduação, da Avaliação das Condições de Ensino e c) o Exame Nacional do Desempenho dos Estudantes, do Provão. A cumulação dos mecanismos de avaliação foi realizada sem considerar que cada um deles é produto de valores e paradigmas divergentes: a visão formativa/emancipatória do PAIUB, fundada na participação e na autonomia institucional, a visão somativa da Avaliação das Condiçôes de Ensino e o mecanismo de ranking do Provão. 
“SINAES" contraditórios: considerações sobre a elaboração e implantação...

A tentativa da conciliação das diferentes concepções de avaliação - e de educação superior - e a indefinição de qual concepção é a adotada como oficial mostram a falta de consenso quanto à política de educação superior do governo Lula, apesar do manifestado no seu Programa de Governo.

Muitas das incongruências do SINAES são resultado da tentativa de implantar uma sistemática de avaliação sem qualquer relação com a elaboração de um projeto de política de educação superior, isto é, sem discussão prévia do tipo de instituições desejado.

Quanto aos resultados em si, ainda não é possível "avaliar a avaliação", pois, por um lado, o SINAES conseguiu ressignificar o ritual anual de divulgação de resultados do Provão, instaurando um outro tempo, reforçando a idéia de processo e formação; por outro, não se conseguiu realizar um ciclo completo de avaliação, tanto que os resultados das avaliações institucional, de curso e dos estudantes, integrados, ainda não foram finalizados.

Ao jornal $O$ Estado de S. Paulo, ${ }^{20}$ o atual presidente do INEP, Reynaldo Fernandes, afirma temer "que o ENADE seja mudado caso o PSDB vença as eleiçôes presidenciais deste ano". Resta saber se esses temores devem ser considerados apenas quanto à possibilidade de mudança de partido ou também quanto à permanência no governo do próprio PT. Esta dúvida origina-se nos avatares ministeriais que evidenciam a falta de consenso no próprio partido no governo, quanto à avaliação e às políticas para a educação superior no país. A própria Lei n. 10.861/ 04, com a coexistência de modelos díspares de avaliação que apresenta, pode servir para um ou outro fim, dependendo dos grupos atuantes no Governo e no Ministério da Educação.

Recebido e aprovado em agosto de 2006.

\section{Notas}

1. Sobre a crise do Estado de bem-estar social e a implantação do Estado neoliberal, ver Laurell (1995), Sader \& Gentili (1995). Sobre a influência dos organismos multilaterais de empréstimo (Banco Mundial, BID, FMI) na formulação das políticas educacionais, ver Sguissardi (2000), World Bank (2004).

2. A Declaração de Bolonha, assinada pelos ministros de educação da União Européia, em 1999, propõe a realização de mudanças nas universidades do bloco para ajustar a formação dos estudantes ao mercado de trabalho, atrair interessados de fora da União Européia 
e desenvolver a mobilidade interna dos estudantes e graduados (Hortale \& Ginés Mora, 2004, p. 938-960).

3. Da Comissão que elaborou o PAIUB participaram membros de entidades, tais como: Associação Nacional de Dirigentes das Instituiçôes Federais de Ensino Superior, Conselho de Reitores das Universidades Brasileiras, Associação Brasileira das Escolas Católicas, Associação Nacional das Universidades Particulares e Associação Brasileira das Universidades Estaduais e Municipais e os seguintes Fóruns de Pro-Reitores de Graduação, Pesquisa e PósGraduação e Planejamento, Administração e Extensão.

4. 46 IES tiveram seu projeto aprovado em 1994 (PAIUb, 1994).

5. Esta seção toma como referência: Barreyro $(2004,2006)$, Rothen (2003a, 2003b) e Rothen e Schulz (2005).

6. Portarias MEC/SESU 11 , de $28 / 04 / 2003$, e 19 , de $27 / 05 / 2003$

7. Comissão presidida por José Dias Sobrinho (UnICAMP), com os seguintes membros: professores Dilvo I. Ristoff (UFSC), Edson Nunes (UCAM), Hélgio Trindade (UFRGS), Isaac Roitman (CAPES), Isaura Belloni (UnB), José E. Q. Telles (Ufpr), José G. de Sousa Júnior (sesu), José M. de R. Pinto (Inep), Júlio C. G. Bertolin (Upf), Maria A. S. Zainko (Ufpr), Maria B. M. Luce (Ufrgs), Maria I. da Cunha (Unisinos), Maria J. J. Costa (UfPA), Mario P. Pederneiras (SESU), Nelson C. Amaral (UfG), Raimundo L. S. Araújo (INEP), Ricardo Martins (UNB), Silke Weber (UFPE), Stela M. Meneghel (furB); e pelos estudantes Giliate Coelho Neto, Fabiana de S. Costa e Rodrigo da S. Pereira, representando a União Nacional de Estudantes (UNE). Daniel Ximenes foi o coordenador executivo, assessorado por Adalberto Carvalho, ambos da SEsu, e Teófilo Bacha Filho, do Conselho Estadual de Educação do Paraná.

8. Helene utiliza como base para a sua crítica o estudo de Rothen (2003b) intitulado $O$ Vestibular do Provão.

$9 . \mathrm{O}$ processo de transformaçāo da proposta da CEA no SINAPES e depois no SINAES pode ser consultado em Barreyro (2004)

10. O Globo, 18 set. 2003.

11. Ver, por exemplo, "MEC estuda fim de nota para Universidade" (Folha de S. Paulo, São Paulo, 6 set. 2003, "O Provão deve ser extinto? Não").

12. O Estado de S. Paulo, 7 set. 2003.

13. Ver o inciso VII do art. 5 e o art 11.

14. Versão publicada em março de 2004.

15. A atribuição é prevista na Lei n. 9.448 de 14/3/1997, que transformou o INEP em autarquia, no Decreto n. 3.879 de 1/8/2001, que aprova a Estrutura Regimental e o Quadro Demonstrativo dos Cargos em Comissão e das Funçōes Gratificadas do INEP, e no Decreto n. 3.860/2001. Sobre a história do INEP e da sua transformação em uma agência de avaliação, ver Rothen (2005).

16. O Decreto n. 2.026/1996 e o Decreto n. 3.860/2001, que substitui o anterior.

17. Por questōes metodológicas, o PAIUB sugeria iniciar a avaliação institucional "como ênfase na área de ensino de graduação, ainda que incluindo, nos instrumentos e indicadores, aspectos relativos ao conjunto da instituição" (PAIUB, 1994 , p. 15).

18. O nome Exame Nacional de Desempenho do Corpo Discente também aparece no Projeto de Lei de Conversão à MP n. 147, de 15 de dezembro de 2003 (Congresso Nacional, 2004).

Educ. Soc., Campinas, vol. 27, n. 96 - Especial, p. 955-977, out. 2006

Disponível em <http://www.cedes.unicamp.br> 
“SINAES" contraditórios: considerações sobre a elaboração e implantação...

19. Esta seção toma como referência Rothen (2006).

20. "ENADE mostrará valor adicionado", O Estado de S. Paulo, São Paulo, 18 maio 2006

\section{Referências bibliográficas}

BARREYRO, G.B. Do Provão ao sinaes: o processo de construção de um novo modelo de avaliação da educação superior. Avaliação, Campinas, v. 9, n. 2, p. 37-49, jun. 2004.

BARREYRO, G.B. Evaluación de la educación superior brasileña: el SINAES. Revista de la Educación Ssuperior, México, v. 35, n. 137, p. 63-73, 2006.

BERTOLIN, J. A transformação do SINAEs: da proposta emancipatória à lei híbrida. Avaliação, Campinas, v. 9, n. 4, p. 67-76, jun. 2004.

BRASIL. Congresso Nacional. Projeto de lei de conversão à Medida Provisória n. 147, de 15 de dezembro de 2003. Avaliação, Campinas, v. 9, n. 1, p. 185-189, jun. 2004.

BRASIL. Ministério da Educação. Comissão Especial de Avaliação da Educação Superior (CEA). Bases para uma nova proposta de avaliação da Educação Superior. Brasília, DF: MEC/INEP/SESU, 2004.

BRASIL. Ministério da Educação. Comissão Nacional de Avaliação da Educação Superior (CONAES). Of. Circ. 033/2005-CONAES/GM/MEC. Disponível em: <www.mec.gov.br/conaes> Acesso em: 30 set. 2005.

BRASIL. Ministério da Educação. Comissão Nacional de Avaliação da Educação Superior (CONAES). Avaliação externa de instituiçōes de educação superior: diretrizes e instrumento. Brasília, DF: CONAES/INEP, 2005. (versão preliminar).

BRASIL. Ministério da Educação. Comissão Nacional de Avaliação da Educação Superior (CONAES) Diretrizes para a avaliação das Instituiçôes de Educação Superior. Brasília, DF: MEC/CONAES/SESU/INEP, $2004 a$.

BRASIL. Ministério da Educação. Comissão Nacional de Avaliação da Educação Superior (CONAES). Roteiro de auto-avaliação institucional. Brasília, DF: MEC/CONAES/INEP, 2004b.

BRASIL. Ministério da Educação. IDES: índice de desenvolvimento do ensino superior; a nova geração da avaliação do ensino superior brasileiro. Brasília, DF: MEC, 2003. (mimeo.). 
BRASIL. Ministério da Educação. Secretaria de Educação Superior. PAIUB: Programa de Avaliação Institucional das Universidades Brasileiras. Brasília, DF: MEC/SESU, 1994.

BUARQUE, C. A avaliação da avaliação. Disponível em: <http:// www.mec.gov.br/acs/pdf/a130103d.pdf>. Acesso em: 13 jan. 2003.

COLIGAÇÃO LULA PRESIDENTE. Uma escola do tamanho do Brasil: caderno temático do programa de governo. São Paulo: Comitê Lula Presidente, 2002.

CONTERA, C. Modelos de avaliação da qualidade da educação superior. In: Dias Sobrinho, J.; RistofF, D. (Org.). Avaliação democrática: para uma universidade cidadã. Florianópolis: Insular, 2002. p. 119-144.

DIAS SOBRINHO, J. Avaliação ética e política em função da educação como direito público ou como mercadoria? Educação \& Sociedade, Campinas, v. 25, n. 88, p. 703-725, out. 2004.

DIAS SOBRINHO, J. Educação e avaliação: técnica e ética. In: DiAS Sobrinho, J.; Ristoff, D. (Org.). Avaliação democrática: para uma universidade cidadã. Florianópolis: Insular, 2002. p. 37-68.

HELENE, O. O INEP e as avaliaçôes. Disponível em: <http://www.inep.gov.br/ imprensa/artigos/inep_avaliacoes.htm>. Acesso em: 5 jun. 2003.

HORTALE, V.A.; GINÉS MORA, J. Tendências das reformas da educação superior na Europa no contexto do processo de Bolonha. Educação \& Sociedade, Campinas, v. 25, n. 88, p. 937-960, out. 2004.

LAURELL, A. (Org.). Estado e politicas sociais no neoliberalismo. São Paulo: Cortez, 1995. p. 151-178.

RODRÍGUEZ GÓMEZ, R. Acreditación ¿Ave fénix de la educación superior en México? In: Odorika, I. (Org.). La academia en jaque: perspectiva política sobre los programas de evaluación de la educación superior en México. México: UNAM-Porrúa, 2004. Disponível em: <http:/ /www.monografias.com/trabajos31>. Acesso em: 30 de jun. 2006.

ROTHEN, J.C. O Instituto Nacional de Estudos Pedagógicos: uma leitura da RBEP. Revista Brasileira de Estudos Pedagógicos, Brasília, DF, v. 86, n. 212, p. 189-224, 2005.

Educ. Soc., Campinas, vol. 27, n. 96 - Especial, p. 955-977, out. 2006 
“SINAES" contraditórios: considerações sobre a elaboração e implantação...

ROTHEN, J.C. O vestibular do professor: certificação e formação de professores da educação básica. Idéias \& Argumentos, Americana, v. 3, n. $7 / 8$, p. 132-150, 2003a.

ROTHEN, J.C. O vestibular do provão. Avaliação, Campinas, v. 8, n. 1, p. 27-37, 2003b.

ROTHEN, J.C. Ponto e contraponto na avaliação institucional: análise dos documentos de implantação do SINAEs. 2006. 29. REUNIĀO ANUAL DA ANPED: Educação, cultura e conhecimento na contemporaneidade: desafios e compromissos: Rio de Janeiro: ANPEd, 2006. p. 1-18.

ROTHEN, J.C.; SCHULZ, A. SINAES: do documento original à legislação. In: 28. REUNIÃO ANUAL DA ANPED: 40 Anos de Pós-Graduação em Educação. Rio de Janeiro: ANPEd, 2005. p. 1-18. Disponível em: <http://www.anped.org.br/28/textos/gt11/gt11195int.doc>

SADER, E.; GENTILI, P. Posneoliberalismo: as políticas sociais e o Estado democrático. São Paulo: Paz \& Terra, 1995.

SGUISSARDI, V. Que lugar ocupa a qualidade nas recentes políticas de educação superior? XIII ENDIPE, 2006, Políticas educacionais, tecnologia e formação do educador: repercussão sobre a didática e as práticas de ensino. In: Anais... Recife: Bagaço, 2006. v. 2 , p. 311-336.

SGUISSARDI, V. Educação superior: o Banco Mundial reforma suas teses e o Brasil reformará sua política? Educação Brasileira, Brasília, v. 22, n. 45, p.11-53, jul.-dez. 2000.

STUBRIN, A. Los mecanismos nacionales de garantia pública de calidad en el marco de la intenacionalización de la educación superior. Avaliação, Campinas, v. 10, n. 4, p. 9-22, 2005.

WORLD BANK. Education. Brazil. Equitable, competitive, sustainable: contributions for debate. Disponível em: <www.woldbank.org>, p. 91116. Acesso em: 5 fev. 2004.

Legislação citada

BRASIL. Decreto 2.026 de 10/10/1996. Estabelece procedimentos para o processo de avaliação dos cursos e instituições de ensino superior. Diário Oficial da União, Brasília, DF, 11 out 1996. 
BRASIL. Decreto 3.860 de 9/7/2001. Dispõe sobre a organização do ensino superior, a avaliação de cursos e instituições, e dá outras providências. Diário Oficial da Uniāo, Brasília, DF, 10 jul. 1997.

BRASIL. Decreto 3879 de 1/8/2001. Aprova a Estrutura Regimental e o Quadro Demonstrativo dos Cargos em Comissão e das Funçóes Gratificadas do Instituto Nacional de Estudos e Pesquisas Educacionais (INEP), e dá outras providências.

BRASIL. Decreto 5.773, de 9/5/2006. Dispõe sobre o exercício das funções de regulação, supervisão e avaliação de instituições de educação superior e cursos superiores de graduação e seqüenciais no sistema federal de ensino.

BRASIL. Lei 9.131 de 24/11/1995. Altera dispositivos da Lei 4.024, de 20 de dezembro de 1961, e dá outras providências. Diário Oficial da União, Brasília, DF, 25 nov. 1995.

BRASIL. Lei 9.448 de 14/03/1997. Transforma o Instituto Nacional de Estudos e Pesquisas Educacionais (INEP) em Autarquia Federal, e dá outras providências. Diário Oficial da Uniāo, Brasília, DF, 15 mar. 1997.

BRASIL. Lei 10.861, de 14/4/2004. Institui o Sistema Nacional de Avaliação da Educação Superior - SinAes e dá outras Providências. Diário Oficial da União, Brasília, DF, 15 abr. 2004.

BRASIL. Medida Provisória 1.159 de 26 de outubro de 1995. Altera dispositivos da Lei 4.024, de 20 de dezembro de 1961 e dá outras Providências.

BRASIL. Medida Provisória 147 de 15 de dezembro de 2003. Institui o Sistema Nacional de Avaliação e Progresso do Ensino Superior e dispõe sobre a avaliação do ensino superior.

BRASIL. Ministério da Educação. Portaria 2.051, de 9/7/2004. Regulamenta os procedimentos de avaliação do Sistema Nacional de Avaliação da Educação Superior.

BRASIL. Ministério da Educação. Secretaria de Educação Superior. Portaria 11 de 28 de abril de 2003. Institui a Comissão Especial com a finalidade de analisar, oferecer subsídios, fazer recomendações, propor critérios e estratégias para a reformulação dos processos e políticas de avaliação do ensino superior e elaborar a revisão crítica dos seus instrumentos, metodologias e critérios utilizados. 